The Duration of Judicial Deliberation: Evidence from Belgium

Peer-reviewed author version

BIELEN, Samantha; MARNEFFE, Wim; Grajzl, Peter \& Dimitrova-Grajzl, Valentina (2018) The Duration of Judicial Deliberation: Evidence from Belgium. In: JOURNAL OF INSTITUTIONAL AND THEORETICAL ECONOMICS-ZEITSCHRIFT FUR DIE GESAMTE STAATSWISSENSCHAFT, 174(2), p. 303-333.

DOI: $10.1628 / 093245617 \times 14926792029174$

Handle: http://hdl.handle.net/1942/23736 


\title{
The Duration of Judicial Deliberation: Evidence from Belgium*
}

\author{
Samantha Bielen ${ }^{1} \quad$ Wim Marneffe ${ }^{2} \quad$ Peter Grajzl $^{3} \quad$ Valentina Dimitrova-Grajzl $^{4}$
}

May 23, 2016

\begin{abstract}
We utilize case-level data from a large Belgian court to study a policy-relevant but thus far empirically unexplored aspect of judicial behavior: the time that a judge takes to deliberate on a case before rendering a verdict. Exploiting the de facto random administrative assignment of filed cases among the serving judges and using survival analysis methods, we find that the duration of judicial deliberation varies not only with measures of case complexity, but also with judge and disputing party characteristics. We further find evidence consistent with the hypothesis that longer judicial deliberation improves the quality of judicial decisions.
\end{abstract}

Keywords: judicial deliberation, case-level data, survival analysis, speed-quality tradeoff, Belgium

JEL Classifications: K40, K41, K49

\footnotetext{
* We are grateful to the staff of the first-instance court of general jurisdiction in Antwerp, and especially to the court president Bart Willocx, for making this project possible. We further thank Patricia Popelier, Giovanni Ramello, and Sarah Verstraelen for valuable comments and discussion.

${ }^{1}$ Faculty of Business Economics, Hasselt University, 3500 Hasselt, Belgium and Faculty of Law, University of Antwerp, 2000 Antwerp, Belgium. Email: samantha.bielen@uhasselt.be

${ }^{2}$ Faculty of Business Economics, Hasselt University, 3500 Hasselt, Belgium. Email: wim.marneffe@uhasselt.be

3 (Corresponding author) Department of Economics, The Williams School of Commerce, Economics and Politics, Washington and Lee University, Lexington, VA 24450, USA and CESifo, Munich, Germany. Email: grajzlp@wlu.edu

4 Department of Economics and Business, Virginia Military Institute, Lexington, VA 24450, USA. Email: dimitrova-grajzlvp@vmi.edu
} 


\section{Introduction}

Given the importance of the judicial systems for economic development (see, e.g., Posner 1998, Feld and Voigt 2003, Chemin 2012) and following the insights of the legal realism movement (see, e.g., Posner 1993, Stephenson 2009), the functioning of courts and judicial decision-making have increasingly become the subject of empirical scrutiny. Accordingly, scholars in law and economics have empirically examined a wide range of court and judicial outcomes. These include, among others, judge productivity (e.g., Choi et al. 2009, Ramseyer 2012, DimitrovaGrajzl et al. 2012b), court efficiency (e.g., Deyneli 2012, Ippoliti et al. 2014), the volume and mode of case disposition (e.g., Beenstock and Haitovsky 2004, Rosales-López 2008; DimitrovaGrajzl et al. 2012a, 2014; El Bialy 2016, Galanter 2004), as well as the overall duration of litigation (e.g., Spurr 1997, Djankov et al. 2003, Di Vita 2012, Boyd and Hoffman 2013, Bielen et al. 2014). ${ }^{1}$ By offering an empirically-grounded understanding of the judiciary, the literature's findings serve as an important input into the ongoing debate about the appropriate course of judicial reform (see, e.g., Botero et al. 2003).

In this paper, we contribute to the existing empirical literature on courts and judges by providing the first empirical exploration of a further policy-relevant, yet thus far unexplored, judicial outcome: the time that judges take to deliberate on a case before articulating a verdict. In continental Europe and other jurisdictions rooted in the civil-law legal tradition, the final deliberative stage in the adjudication of a civil case is left to the judge. ${ }^{2}$ The time that judges take to deliberate on a case prior to announcing the verdict therefore either facilitates timely dispute resolution or, when judicial deliberation takes a long while, contributes to court delays and thereby increases the costs of the legal system (see, e.g., Johnson 1997, Chemin 2012: 460, Fenn and Rickman 2014: 245).

\footnotetext{
${ }^{1}$ For a recent overview of the literature on court efficiency, see Voigt (2016).

${ }^{2}$ In contrast, in common-law jurisdiction the final deliberative stage about the merits of the case is often left to the jury.
} 
Belgium, the focus of our paper, represents a particularly interesting case for the study of the duration of judicial deliberation. Court delays have been a persistent concern in Belgium (see, e.g., Bielen et al. 2015). Consequently, the time that judges take to deliberate on cases has been the subject of an intense policy debate and controversy (see, e.g., Hoge Raad voor de Justitie 2014, Belgische Senaat 2015). Yet to date, there exist no systematic empirical analyses of the duration of judicial deliberation and its determinants in Belgium or elsewhere.

We fill the abovementioned gap in the literature by drawing on case-level data from the largest first-instance court in the Flanders region of Belgium. Our analysis addresses the following questions: How much time do judges take to deliberate on a case? What party, judge, and other characteristics of a case help explain the duration of judicial deliberation? Is there any association between the duration of judicial deliberation and the quality of judicial decisions?

Our data show that, in the majority (nearly 70 percent) of cases, judges complete their deliberation within the procedurally mandated thirty-day period. However, we also find that judges often (in about 11 percent of the cases) either fail to complete their deliberation within the desired deadline or finish their deliberation notably faster than required, within three weeks or earlier (in nearly 12 percent of the cases). Thus, there exists non-trivial variation in the length of time that judges spend on deliberation.

Exploiting the de facto random administrative assignment of filed cases among the judges serving at the court and using methods of survival analysis, we demonstrate that the duration of judicial deliberation is robustly positively associated with two measures of case complexity: the appointment of an expert and the length of summary pleadings that the judge must analyze to render a verdict. A subset of judge and disputing party characteristics also matters. We find, for example, that the duration of judicial deliberation is shorter for cases that are adjudicated by judges with prior experience as judicial interns or as substitute judges than for cases adjudicated 
by judges without such experience, ceteris paribus. Furthermore, even after controlling for a range of case characteristics and judge fixed effects, cases where at least one party is a legal person tend to be deliberated on longer than cases where all involved parties are physical persons. These findings resonate with different subsets of the prior literature that has highlighted the importance of judge characteristics and extralegal factors for adjudicatory outcomes (see, e.g., Schneider 2005, Teitelbaum 2006, Choi et al. 2011, Dimitrova-Grajzl et al. 2012b, Danziger et al. 2011, Ramseyer 2012, Schanzenbach 2015).

Finally, to provide a further perspective on the duration of judicial deliberation, we examine if the length of time that judges deliberate on cases is systematically related to the quality of judicial decisions. Indeed, an understanding of whether there exists a tradeoff between speed and quality in judicial decision-making is instrumental to sound policy-making. Accordingly, existing literature (see Posner 1996, Rosales-López 2008, Coviello et al. 2015, Dimitrova-Grajzl et al. 2012b, 2016) has examined whether there exists a quantity-quality tradeoff in court case resolution. No contribution, however, has studied the relationship between the duration of judicial deliberation and measures of quality of judicial decisions.

Addressing sample selection concerns and controlling for the full range of party and case characteristics, as well as judge fixed effects, we find that the duration of judicial deliberation is negatively associated with the prospects of appeal and verdict reversal, respectively, as two commonly employed measures of quality of judicial decision-making (see, e.g., Mitsopoulos and Pelagidis 2007, 2010; Coviello et al. 2015, Posner 2000, Choi et al. 2012, Dimitrova-Grajzl et al. 2012b, 2016), although only the association between the duration of judicial deliberation and verdict reversal is statistically significant. Our results are thus consistent with the hypothesis that longer judicial deliberation improves the quality of judicial decisions and, therefore, that any 
benefits from incentivizing judges to deliver faster verdicts should be weighed against the costs from the expected decrease in the adjudicatory quality.

The rest of the paper is organized as follows. Section 2 provides a brief institutional background on the Belgian judiciary and civil procedure. Section 3 introduces our data and articulates our hypotheses. Sections 4 and 5 describe our empirical approach and present the results. Section 6 concludes.

\section{The Belgian Judicial System: A Brief Institutional Background ${ }^{3}$}

\subsection{Court System}

Belgium has a civil law tradition which is largely influenced by the French legal system. The higher courts, which encompass the courts of appeal, are organized on the level of five judicial areas. These judicial areas are divided into 27 judicial districts, each with a first-instance court of general jurisdiction, a labor court, a commercial court, and a police court. Judicial districts are in turn divided into 187 judicial cantons, each with a justice of the peace court. The first-instance courts of general jurisdiction are subdivided into a civil, criminal and family bench. Each of the ten Belgian provinces and the capital district (Brussels) has a court of assizes, which hears the most severe criminal cases. Finally, the court of cassation serves as the court of last instance for review of the lawfulness of judicial rulings.

In this paper we focus on cases adjudicated at the civil bench of the first instance court of general jurisdiction located in Antwerp in the Flanders region. The Antwerp court of first instance is the largest first-instance court of general jurisdiction in the Flanders region of Belgium. The court hears about 20 percent of all incoming civil cases initiated at the firstinstance courts of general jurisdiction in the Flanders region or nearly ten percent of all civil cases filed at the first-instance courts of general jurisdiction in Belgium.

\footnotetext{
${ }^{3}$ This section draws on various parts of the Belgian Constitution and Judicial Code.
} 


\subsection{Judges}

To become a judge in Belgium, a candidate must be a Belgian national. Candidates without any professional legal experience (i.e. recent law school graduates) must pass an entrance exam and complete a mandatory judge training program that includes a judicial internship. Candidates with prior legal experience must, depending on the extent of their legal experience, pass either a professional competence or an aptitude exam.

Judges are appointed by the government upon the formal recommendation of the High Council of Justice. Consistent with the constitutionally guaranteed independence of the judiciary, judges are appointed for life and are expected to retire at age 67. Transfer of a judge from one court to another can only take place via appointment to a new position (e.g. as a judge in another court) and with the judge's consent. Belgian law also allows a lawyer with sufficient professional experience to substitute for an absent judge under specific circumstances (e.g. due to prolonged illness of the judge).

Judicial salaries are fully regulated by law. Within first-instance courts of general jurisdiction, salaries are based solely on the length of judicial experience. Only court presidents and vice-presidents are eligible for salary bonuses. Judges are subject to regular performance evaluation. The first performance evaluation takes place one year after the initial appointment; subsequent evaluations take place every three years. Aside from professional knowledge, collegiality, and integrity, an important evaluation criterion is the effectiveness of administering justice which includes the commitment to resolving cases without undue delay. If a judge receives a negative evaluation, the judge's salary increase may be withheld for up to six months. Judges, however, are never eligible for salary bonuses. 


\subsection{Civil Procedure}

Civil court proceedings start with the filing of a complaint at the court, usually by means of a writ of summons in which the plaintiff provides a description of the dispute. Shortly after the summons is served by the bailiff, the disputing parties (or their legal representatives) must appear at the introductory hearing during which parties can jointly draft a pleading calendar; in the absence of an agreement among the parties concerning the pleading deadlines, the judge prepares the pleading calendar upon his or her own motion. The pleading calendar sets out the deadlines for both the plaintiff and the defendant to submit (one or multiple) written pleadings and the date of the main trial hearing. Written pleadings are of central importance in Belgian civil procedure in that written pleadings contain all of the key information about the case that the adjudicating judge takes into account to deliver the verdict. By law, the judge is not required to take into account any of the oral arguments presented during the hearings when deciding on the merits of the case.

In complex cases evidence is often evaluated by court experts. The court requests expert advice either on the judge's own motion or on the request of a disputing party. If an expert is appointed, the judge imposes a deadline for the expert to submit the final report. Once the expert report is submitted, the disputing parties may exchange pleadings in which they discuss the expert's findings.

After the final hearing the judge formally closes the debate in order to deliberate on the case. At that point, the disputing parties are no longer allowed to submit evidentiary documents or exchange pleadings. Simultaneously with the closing of the debate, the judge sets a date for a hearing at which the judge is expected to announce the verdict. The judge, however, can ex post postpone the pronouncement of the verdict if he or she is not ready to deliver the verdict by the originally announced date. 


\subsection{Judicial Deliberation}

Prior to 2007, Belgian legislation specified no timeline for when a judge must complete deliberation and announce a verdict. The system was heavily criticized for causing undue delays in the administration of justice. Accordingly, the reformed Civil Procedure Code introduced procedural rules governing judicial deliberation. Since 2007, the judge's announcement of the verdict can take place no later than one month (i.e. 30 days) after the judge closes the debate at the last hearing. In an attempt to enforce this rule, the court clerks maintain a current list of all cases for which judicial deliberation exceeds the 30-day deadline. Judges in violation of this rule are asked to submit a report to the court president explaining the excessive duration of their deliberation. If the deliberation time exceeds three months, the court president may further intervene by requiring the judge to present an explicit plan for addressing the delay and by levying disciplinary sanctions (e.g. withholding of judge's salary). The court's president involvement is recorded and is taken into consideration in the event of disciplinary proceedings against the violating judge and as part of the judge's performance evaluation.

In rendering the verdict, the judge is expected to take into account only the final ('synthesis' or 'summary') pleading by each party, which incorporates all previous pleadings submitted by the party. The outcome of the judge's deliberation is a written verdict. The verdict must explain and justify the judge's decision and demonstrate that the judge has carefully considered the arguments presented by the disputants. Inadequately justified verdicts may be repealed if a party's appeal reaches the court of cassation. 


\section{Data, Variables, and Hypotheses}

\subsection{Dataset}

To study the duration of judicial deliberation, we draw on a random sample of cases filed at the first instance court of general jurisdiction in Antwerp. We were granted permission to access the court files at the Antwerp court for the purpose of academic research.

Our dataset covers two types of cases: contract cases and construction cases, which together represent nearly one half of all cases filed at the civil bench of the Antwerp court of first instance. Contractual disputes occur across industries, and hence can be thought of as widely representative of the Belgian economy. Construction cases, in contrast, represent a specialized subset of contract cases that are tracked separately in the official Belgian court statistics in part due to concerns about excessive delays. Delayed resolution of construction cases has, for example, been argued to send a negative signal to foreign investors (see, e.g., Iyer et al. 2008).

The civil bench of the Antwerp court is organized in chambers. Each chamber handles disputes of a particular type. Our dataset consists of cases resolved in four construction chambers and three contract chambers. Filed cases are allocated to chambers by the judge presiding at the introductory court session. ${ }^{4}$ The choice of which particular construction chamber or contract chamber will oversee the resolution of the dispute is based on the chambers' current workload. The caseload of each chamber is handled by multiple judges and each judge presides over trial hearings in a given chamber on certain days or hours of the week. Thus, within a chamber, the assignment of cases to judges is de facto independent of case and judge characteristics. (In Section 4.1 we provide statistical evidence in support of this claim.)

Belgian courts currently lack a comprehensive computerized case management system. As a consequence, the data we use in our analysis were hand-collected from the archived case

\footnotetext{
${ }^{4}$ If a dispute is deemed particularly straightforward, it is adjudicated immediately at the introductory court session. Such fast-track cases are excluded from our analysis.
} 
files. Our starting sample consisted of above one thousand randomly selected contract and construction cases that were initiated on, or after, January 1, 2008 and were either already resolved or still pending court verdict by October 1, 2014. To determine how many construction and how many contract cases filed at a court during this time period should be included in our starting sample we used stratified random sampling. The size of the sampled strata (construction and contract cases) reflected the relative proportion of each stratum in the population of all types of first-instance cases adjudicated at the Antwerp court. Given our focus on the duration of judicial deliberation, we then dropped all cases that were dismissed on procedural grounds, withdrawn, settled, or disposed via default judgment. We further dropped cases with missing or evidently erroneous records.

Our final sample consists of 631 cases for which the court verdict was already announced by October 1, 2014 (596 cases), or, alternatively, judicial deliberation had begun but was still pending on October 1, 2014 (35 cases). This includes 370 contract cases, of which judicial deliberation had begun but the verdict was still pending for 23, and 261 construction cases, of which judicial deliberation had begun but the verdict was still pending for 12 . Table 1 defines the variables. Table 2 presents the descriptive statistics.

\subsection{The Duration of Judicial Deliberation}

The outcome variable of interest, the duration of judge deliberation, is the time elapsed between the last hearing and the announcement of the verdict. The judge announces the expected date of the verdict at the last trial hearing. The announced date, however, need not always equal the date when the verdict is actually proclaimed, since the judge might choose to extend the duration of his or her deliberation. Our measures of the duration of judge deliberation is the number of days elapsed between the last trial hearing and the day when the verdict was actually proclaimed. 
Figure 1 and Table A1 in the Appendix show the distribution of judge deliberation times for the cases included in our sample. 88 percent of the verdicts are rendered within the mandated 30-day period. This finding is not surprising given the current procedural rules and monitoring mechanisms governing judicial deliberation (see Section 2.4). Nevertheless, judges fail to meet the one-month deadline in approximately 12 percent of the cases. Furthermore, in another 12 percent of the cases, judges completed their deliberation rather quickly, rendering a verdict within three weeks. Overall, therefore, there exists non-trivial variation in the duration of judicial deliberation in our data (the coefficient of variation equals 0.47 ).

The mean number of days for a judge to render a verdict is 30.2 days. The mean time between filing of the case and the start of judge deliberation is about 475 days for our sample. Thus, judge deliberation on average constitutes a relatively small part of the total case duration. As such, judicial deliberation in general cannot be viewed as the primary cause of court delays at the Antwerp court. However, excessive judicial deliberation certainly can contribute to court delays. In our sample, for example, the duration of judicial deliberation exceeded the 90-day threshold for 17 resolved cases (see Table A1).

Figure 2 presents the Kaplan-Meier estimate of the survivor function, that is, the probability that the judge renders the verdict later than a certain number of days since the last hearing. The survivor function decreases gradually for the first twenty days, drops sharply at around thirty days, and gradually decreases thereafter.

Figure 3 shows the non-parametric smoothed estimate of the verdict hazard, that is, the instantaneous conditional probability that the verdict is rendered at a given number of days since the last hearing given that it has not occurred until that point in time. The verdict hazard increases at a decreasing rate between twenty and thirty days since the start of judge's 
deliberation, and then decreases at an increasing rate for the next twenty days. Finally, the hazard rate again increases after about sixty days since the last hearing.

\subsection{Explanatory Variables and Hypotheses}

Our explanatory variables are all time-invariant and capture the characteristics of the disputing parties, the case, and the judge. In the absence of prior empirical literature on the duration of judicial deliberation, we develop our hypotheses by drawing on the general insights provided by the existing literature on judicial behavior and by taking into account the Belgian institutional context.

Disputing party characteristics. The majority of the cases in our sample (62 percent) involve only one plaintiff and one defendant. Disputes involving multiple parties tend to be more complex. All else equal, we would thus expect (Hypothesis 1) that it takes a judge more time to deliberate on cases featuring multiple parties on either the plaintiff or defendant side than to deliberate on cases featuring a single plaintiff and a single defendant.

82 percent of the cases in our sample involve at least one legal person. Cases involving government on either plaintiff or defendant side are rare (1.1 percent). Businesses and government are typically repeat players, which tend to come out ahead in litigation (see, e.g., Galanter 1974, George and Epstein 1992). On the one hand, judges might allocate more of their time to cases where the disputing parties are regarded as more socially visible or esteemed. Therefore, disputes involving at least one legal person or government might result in longer deliberation times (Hypothesis 2a). On the other hand, the pressure on judges to complete their deliberations quickly may be greater when the disputing parties include businesses or government than when all disputing parties are individuals. Thus, disputes involving at least one legal person or government might also result in shorter judicial deliberation (Hypothesis 2b) 
In 75 percent of the cases in our sample, all parties are represented by a lawyer. On the one hand, we would expect pleadings prepared by a lawyer to be on average more elaborate and complex than pleadings drafted by self-represented parties. Absence of lawyer representation could, all else equal, therefore lead to shorter judicial deliberation (Hypothesis 3a). Yet on the other hand, pleadings drafted by legally inexperienced, self-represented parties are likely to require greater judicial effort in assessing the merits of the parties' argument; thus (Hypothesis 3b), absence of lawyer representation could also lead to longer judicial deliberation.

Case characteristics. The average value of the claim in our sample is a little less than EUR 30,000. However, the variation in the value of this variable is large. For example, while 90 percent of the claims are smaller than EUR 55,000, nine claims (1.4 percent of cases) exceed EUR 400,000. On the one hand, we would expect judicial deliberation to take longer when the stakes are higher (Hypothesis 4a). Yet on the other hand, higher stakes also imply greater pecuniary and non-pecuniary losses for the plaintiff in the event of delay in adjudication; thus, higher stakes may also induce the judge to speed up his or her deliberation (Hypothesis 4b).

Court experts are involved in 13.5 percent of our cases. Involvement of an expert indicates that the case is complex, which in turn requires the judge to invest significant effort in deliberation about the merits of the case. Moreover, when an expert assessment is provided, the judge not only has to motivate his decision based on the pleadings of the parties, but also based on the arguments raised by the expert. We, therefore, hypothesize (Hypothesis 5) that the appointment of an expert increases the duration of judicial deliberation.

The parties are in charge of the pleadings calendar in 56 percent of the cases. Who sets up the pleadings calendar can affect the duration of judicial deliberation. On the one hand, the fact that the judge has had to set up the calendar because the parties were unable to agree on the deadlines may be an indication of a high level of antagonism between the disputing parties and, 
hence, imply that the case is contentious and complex. Judicial control over the pleadings calendar thus possibly increases judge's deliberation time (Hypothesis 6a). Yet on the other hand, when the pleading calendar is prepared by the judge, the judge has to take into account the initial facts about the dispute and the parties' preferences concerning the calendar. Hence, the judge has already had an opportunity to get acquainted with the case. Accordingly, greater familiarity with the case at the beginning of the process might shorten the duration of judicial deliberation (Hypothesis 6b).

9.5 percent of the cases in our sample required more than two hearings to resolve the case. On the one hand, the number of hearings could be viewed as another proxy for case complexity and, thus, multiple hearings should lead to longer judicial deliberation (Hypothesis 7). Yet on the other hand, multiple hearings are sometimes scheduled upon parties' request for a variety of personal reasons and without a clear effect on the duration of judge deliberation.

The average number of total pages in the synthesis pleadings (i.e. the sum of pages of synthesis pleadings of plaintiffs and defendants) in our sample is 17. However, there is significant variation across the cases in our sample with regard to the length of the pleadings. Nearly ten percent of the cases in our sample were resolved without pleadings. Other cases feature long pleadings: the number of pages exceeds 20 in 25 percent of the cases in our sample, and 40 pages in seven percent of the cases. The weighing of the pros and cons of the arguments put forth in the pleadings requires the judge to exert cognitive effort and is time-consuming per se. We hypothesize (Hypothesis 8) that the duration of judicial deliberation increases with the number of pages in the synthesis pleading.

About two percent of the cases involve a dispute that entailed a successfully appealed, and therefore annulled, default judgment. The annulment of a default judgment provides the judge with an opportunity to get acquainted with the case. We hypothesize (Hypothesis 9) that 
cases involving an appealed default judgment ceteris paribus result in shorter duration of judicial deliberation than cases without a default judgment.

Five percent of the cases in our sample were initially filed at another court, which then transferred the case to the Antwerp court for various jurisdictional reasons and at different stages of the proceeding. The judge might require more time to study the case that was not assigned to him or her from the very beginning. We hence expect (Hypothesis 10) the duration of judicial deliberation to be longer if a case had been initiated at a different court.

Judge characteristics. The 631 cases in our data are adjudicated by 19 different judges. $36 \%$ of the cases in our sample were resolved by a female judge. Evidence about the effect of a judge's gender on various adjudicatory outcomes is overall mixed, with some studies (see, e.g., Davis et al. 1993, Peresie 2005, Boyd et al. 2010) suggesting that judge's gender matters and others (see, e.g., Gruhl et al. 1981, Choi et al. 2011, Dimitrova-Grajzl et al. 2012b) that it does not. We, therefore, do not articulate a hypothesis about the expected association between judge's gender and deliberation time and instead let the data speak for itself.

The average age of a judge at the time of filing of a case in our sample is 43.3 years. There exists a number of reasons why a judge's age might impact adjudicatory outcomes. For example, promotion to a higher court, which results in a salary increase, increases lifetime earnings of an older judge by a smaller amount than for a younger judge; hence, an older judge might be less concerned about promotion and consequently have lower productivity than a younger judge (see, e.g., Choi et al. 2012, Schneider 2005). Another reason for a negative relationship between age and productivity is the burnout effect (Teitelbaum 2006, Christensen and Szmer 2012). Accordingly, we hypothesize (Hypothesis 11) that, all else equal, cases adjudicated by older judges entail longer judicial deliberation than cases adjudicated by younger judges. 
A randomly drawn case in our sample is adjudicated by a judge with 4.5 years of judicial experience. More experienced judges may be able to resolve cases with greater skill and speed (see, e.g., Teitelbaum 2006, Choi et al. 2009, 2010; Dimitrova-Grajzl et al. 2012b). Accordingly, we hypothesize (Hypothesis 12) that judicial deliberation is completed faster when the case is adjudicated by a judge with longer judicial experience.

We have information about the type of judges' prior judicial experience. Specifically, five judges in our sample have served as substitute judges (see Section 2.2), eight have worked as judicial interns, three have served as appellate judges, and one judge has served as court president. Judges who worked as substitute judges or judicial interns likely have additional relevant judicial experience beyond that obtained once they became full-time judges. Former court presidents are particularly familiar with the problem of delays and may choose to lead by example. We thus expect (Hypothesis 13) that cases adjudicated by judges with prior experience as a substitute judge, judicial intern, or court president result in shorter duration of judicial deliberation than cases adjudicated by judges without such experience. Finally, given their familiarity with the appeal process, judges with adjudicatory experience at an appellate court may be more inclined to draft particularly thorough verdicts in order to reduce the risk of higher court reversal. We hypothesize (Hypothesis 14) that cases adjudicated by judges with prior experience as appellate judge result in longer duration of judicial deliberation than cases adjudicated by judges without such experience. Table 3 summarizes our hypotheses concerning the effect of specific covariates on the duration of judicial deliberation.

Finally, we have verified that none of the judges in our sample have completed a postgraduate degree and that all judges obtained their university-level education in Belgium, where, unlike in the U.S. or Japan (see, e.g., Ramseyer 2012), there is comparatively limited variation in 
reputation and quality across university programs. Consequently, we do not control for the level of education of judges or the university where that education was obtained.

\section{What Explains the Duration of Judicial Deliberation?}

\subsection{Empirical Approach}

To examine the determinants of the duration of judicial deliberation we use survival analysis. In contrast to standard regression methods, such as ordinary least squares (OLS) estimation, survival analysis addresses the issue of the non-normal distribution of duration times (see Figure 1 and Table A1). In addition, the use of survival methods allows us to incorporate cases for which judicial deliberation has already begun but has not yet been concluded. Because cases pending verdict might differ systematically from already resolved cases, inclusion of pending cases mitigates the sample selection bias that would arise if the estimating sample was comprised solely of resolved cases.

Our baseline estimation method is the Cox (1972) model as the most widely utilized empirical approach in the survival analysis literature (see, e.g., Cameron and Trivedi 2005, Cleves et al. 2010). Unlike in the case of fully parametric models, in the semi-parametric Cox model the baseline hazard is given no particular parameterization and need not be estimated in order to determine the ceteris paribus effect of a particular explanatory variable on the hazard rate. Exponentiated coefficients have the interpretation of the ratio of the hazards for a unitchange in the explanatory variable in question. A positive (negative) coefficient therefore corresponds to hazard ratio greater (smaller) than one, which in turn implies that the variable in question increases (decreases) the verdict hazard or, equivalently, decreases (increases) duration of judicial deliberation.

We estimate two different empirical specifications. In the first specification we aim to highlight the role of the role of party and case characteristics. To control for all possible judge- 
level idiosyncrasies in judicial deliberation, we include a full set of judge fixed effects. In the second specification we aim to elucidate the role of judge characteristics. To this end, we control for chamber (rather than judge) fixed effects and exploit the fact that, within a chamber, the administrative allocation of cases to judges is independent of judge, party, and other case characteristics. Table A2 in the Appendix reaffirms this claim by presenting a summary of tests of independence between judge identity and eleven different case characteristics (introduced in Section 3.3), conditioning on the chamber. Independence is rejected in less than seven percent of the tests when we do not address the statistical concerns that arise in multiple hypothesis testing (see, e.g., Benjamini and Hochberg 1995) and in none of the tests when we address such concerns. We conclude that, within each chamber, cases are indeed assigned to judges randomly. Chamber fixed effects also absorb any effect of case type (contractual versus construction disputes are adjudicated in different chambers; see Section 3) as well as chamber-specific caseload, and, therefore, average caseload per judge.

In both specifications, we include the full set of dummies for the year in which a case was filed at the court to control for any potential year-specific effects (e.g. new laws, reforms, initiatives or practices) on the duration of judicial deliberation. We base statistical inference on heteroscedasticity-robust standard errors clustered at the level of a judge to account for possible dependencies across cases handled by the same judge.

\subsection{Results}

The results in the form of hazard ratios (i.e. exponentiated coefficients) and the associated standard errors are presented in Table 4. In the specification in column (1), we control for judge fixed effects and, thus, assess the role of party and case characteristics. We find, first, that party identity exhibits a statistically significant effect on verdict hazard. Judicial deliberation is longer

for cases where at least one party is a legal person or government entity. Based on the estimates 
in column (1), relative to the case where all parties are individuals, presence of at least one legal person ceteris paribus decreases verdict hazard by about 12 percent; presence of government among the disputing parties decreases verdict hazard by approximately 21 percent. Note that these estimates are obtained after controlling for a range of measures of case complexity, such as the involvement of a court expert, the number of parties, and the length of the synthesis pleading. Thus, one interpretation of these results, consistent with Hypothesis 2a, is that judges discriminate among cases and allocate more of their time to cases where the disputing parties are perceived as more socially visible or esteemed.

Second, consistent with Hypothesis 4b, the duration of judicial deliberation is ceteris paribus shorter for cases involving higher stakes. The effect of stakes, however, is relatively small in magnitude. All else equal, an increase in the stakes of EUR 10,000 (approximately one third of the mean value) increases verdict hazard by about one percent.

Third, appointment of an expert and the number of pages in the summary pleading as proxies for case complexity are, consistent with Hypotheses 5 and 8, both associated with greater duration of judicial deliberation. Appointment of an expert ceteris paribus reduces verdict hazard by 19 percent. Similarly, every additional page of summary pleadings, which the judge is required to read before articulating the verdict, decreases verdict hazard by about one percent, ceteris paribus.

Fourth, the number of disputing parties, parties' legal representation, whether parties were ever in charge of the pleading calendar, the number of recorded hearings, whether a case was tried after an appealed default judgment, and whether a case was initiated at a different court do not exhibit a statistically significant effect on the duration of judicial deliberation.

In the specification in column (2), we instead control for chamber fixed effects and focus on the role of judge characteristics. We find no statistically significant effect of judge's gender 
and age on the duration of judicial deliberation. These results resonate with the findings of a subset of the empirical literature that has likewise not found an effect of judge's gender (e.g., Gruhl et al. 1981, Davis et al. 1993, Choi et al. 2011, Dimitrova-Grajzl et al. 2012b) or age (e.g., Christensen and Szmer 2012, Schneider 2005) on adjudicatory outcomes.

We also find no effect of the length of judicial experience. Consistent with Hypothesis 13, however, the type of judge's prior adjudicatory experience does matter for the duration of judicial deliberation. Based on the estimates in column (2), holding all else equal verdict hazard is respectively 25 and 21 percent greater for cases adjudicated by a judge with prior experience as judicial intern and substitute judge than for cases adjudicated by a judge without such experience. We also find that verdict hazard is 35 percent greater for cases adjudicated by a judge with prior experience as court president, although this effect is identified off a single judge and, as such, should be interpreted with caution. Verdict hazard for cases adjudicated by judges with prior adjudicatory experience at an appellate court, however, is not statistically significantly different from verdict hazard for cases adjudicated by judges without prior experience at an appellate court.

\subsection{Assessing the Proportional Hazards Assumption and Alternative Model Specifications}

The Cox model assumes that each covariate has a proportional and constant (i.e. time invariant) effect on the hazard rate. Non-proportional hazards can arise if the size of a covariate's effect changes over time. Non-proportional hazards result in a misspecified model and can give rise to erroneous inference about the effect of covariates. To test the proportional hazards assumption we use the global test proposed by Grambsch and Thernau (1994). The test is based on a Chisquared distributed test statistic (see Cleves et al. 2010). Rejection of the null hypothesis implies a violation of the proportional hazards assumption. 
The value of the Chi-squared test statistic and the associated p-value are, respectively, 4.12 and 0.999 for model specification in Table 4, column (1), and 4.81 and 0.999 for model specification in Table 4, column (2). The failure to reject the null hypothesis that the proportional hazards assumption holds lends credibility to our empirical approach.

We also examined several alternative model specifications to explore the robustness of our findings. Table 5 reports the results. First, we estimated a stratified Cox model which provides an alternative to the inclusion of chamber or judge fixed effects as means of taking into account unobserved heterogeneity (see, e.g., Cleves et al. 2010: 197-201). In a stratified Cox model, we allow the baseline settlement hazards to differ (i.e. to have a different shape) either by chamber (when focusing on the role of judge characteristics) or by judge (when focusing on the role of case characteristics) instead of controlling for chamber or judge fixed effects, respectively (in which case the chamber or the judge, respectively, exhibits a multiplicative effect on the common baseline judgment hazard). The results are reported in columns (1) and (2) of Table 5. Estimation of a stratified instead of a non-stratified Cox model (Table 4) results in loss of statistical significance of the effect of stakes ( $p$-value for the estimated hazard ratio on Claim Value in column (1) of Table 5 equals 0.168 ) but does not change any of our other qualitative conclusions regarding the effect of various covariates on verdict hazard.

Second, we estimated a series of parametric hazard models in which the baseline hazard is, unlike in the semiparametric Cox model, given a parametric representation. The advantage of a parametric over a semiparametric hazard model stems from the fact that, if the baseline hazard is specified accurately, the parameter estimates based on the parametric model will generally be more precise than estimates from the semiparametric model where the underlying timedependency of the hazard function is left unspecified (see, e.g., Cleves et al. 2010). We estimated the exponential, Gompertz, and Weibull models which are all specified in the proportional- 
hazards metric; this feature renders the results based on the three parametric models directly comparable to the results obtained using the semiparametric Cox model (Table 4). Based on the standard Akaike and Bayesian information criteria, the Weibull model fits the data best. Columns (3) and (4) in Table 5 therefore report the results using the Weibull model. Overall, the results are qualitatively and quantitatively very similar to the results based on the Cox model. In comparison with the estimates in Table 4, the estimates in columns (3) and (4) of Table 5 feature a statistically insignificant effect of the presence of government among disputing parties and judge's prior experience as court president. Consistent with Hypothesis 9, we also find a statistically significant positive effect on verdict hazard of a case being resolved through trial after an appealed default judgment.

Third, we examined the consequences of directly modeling unobserved heterogeneity by estimating an unshared frailty model, where the multiplicative effect of unobserved heterogeneity on the hazard function is modeled as observation-specific (rather than groupspecific). For reasons of identifiability, unshared frailty models do not exist within the semiparametric Cox regression framework (see Cleves et al. 2010: 156). We therefore estimated a Weibull model with unshared frailty that follows an inverse-Gaussian distribution. The results are reported in columns (5) and (6) of Table 5 and are both qualitatively and quantitatively very similar to the results based on the Weibull model without unshared frailty (columns (3) and (4)). ${ }^{5}$

In sum, the results concerning the presence of legal persons among disputing parties, involvement of court expert, the length of summary pleadings, and judge's prior experience as judicial intern or substitute judge based on the Cox model and presented in Section 4.2 (Table 4) are robust to a wide range alternative model specifications. In contrast, the results about the

\footnotetext{
5 We also attempted to estimate shared frailty models (see, e.g., Cleves at al. 2010). Shared frailty model estimates, however, often failed to converge, a problem already noted in the related literature (see, e.g., Boyd and Hoffman 2012: fn. 24). When the estimates did converge, the estimate of the shared frailty variance was statistically insignificant, a finding suggesting that unobserved group-level heterogeneity is not a concern and that, as such, it may safely be ignored (see Cleves et al. 2010: 199).
} 
presence of government among disputing parties, stakes, whether the case involved an appealed default judgment, and judge's prior experience as court president are not robust across specifications.

\section{Is There a Tradeoff Between the Speed of Judicial Deliberation and the Quality of Adjudicatory Decisions?}

Judicial deliberation contributes to the overall duration of case resolution. Because court delay is costly (see, e.g., Johnson 1997, Chemin 2012: 460, Fenn and Rickman 2014: 245), faster judicial deliberation is ceteris paribus preferred to slower judicial deliberation. Reducing the time that judges spend on deliberation, however, may come at the expense of the quality of judicial verdicts. Thus, an encompassing assessment of the length of time that judges spend on deliberation necessitates an understanding of the potential tradeoff between the time that judges take to deliberate on cases and the quality of the judges' decisions.

\subsection{Empirical Approach}

We examine the association between the duration of judicial deliberation and two commonly employed proxies for the quality of judicial decisions, available in our dataset: if a case was appealed and if the court's decision was overturned by a higher court providing the case had been appealed (see, e.g., Rosales-López 2008, Mitsopoulos and Pelagidis 2007, 2010; Choi et al. 2012, Coviello et al. 2015, Dimitrova-Grajzl et al. 2012b, 2016). The occurrence of an appeal and the reversal of a verdict, of course, depend on a variety of factors, including parties' subjective expectations about the case and the preferences of the appellate judge, respectively. As such, the incidence of appeal and reversal are admittedly imperfect proxies for the quality of judicial decisions (see, e.g., Choi et al. 2012, Coviello et al. 2015; Dimitrova-Grajzl et al. 2012b: 232). Subject to these caveats, evidence of a negative association between the duration of judicial deliberation and the occurrence of an appealed or overturned verdict, respectively, is indicative 
of the presence of a tradeoff between the speed of judicial deliberation and the quality of judicial decisions.

In conducting the analysis, we restrict the sample to the cases for which the verdict had been rendered sufficiently long ago so that the filing of an appeal and the adjudication of the appealed decision at the appellate court have had a chance to take place by the time of completion of our data collection (March 2016). According to Belgian law, a party can appeal within one month from the moment that the court bailiff has served the judgment to the losing party. The exact timing of when the bailiff serves the judgment to the losing party depends on the winning party's decision. Based on official Belgian court statistics for the cases adjudicated at the Antwerp court of first instance, 80 percent of appeals take place within 130 days since the verdict and the average duration for a case adjudicated at the Antwerp appellate court in year 2013 was 502 days. We, therefore, drop from the sample all cases that were resolved at the first instance after March 1, 2012, that is, less than four years prior to completion of our data collection. ${ }^{6}$

We then estimate the relationship between the duration of judicial deliberation and the event that the case is appealed and overturned, respectively. Much like tried cases are a select subset of all disputes (see, e.g., Priest and Klein 1984), appealed cases are a select subset of all resolved court cases. That is, parties' decision to file an appeal may be correlated with unobserved determinants of parties' success at the appellate stage. To address this issue, we use a sample selection model and apply Heckman's (1979) two-step method. The first stage ('selection equation') is a probit regression where the outcome variable Appealed takes on the value 1 if the case was appealed and 0 otherwise (see Table 1). The second stage ('outcome equation') is a linear probability model for the outcome variable Overturned that equals 1 if the first-stage

\footnotetext{
${ }^{6}$ Our findings are robust to varying this date. Detailed results of sensitivity analysis with respect to varying the size of the sample are available upon request.
} 
verdict was overturned at the appellate stage and 0 otherwise (see Table 1). We estimate an OLS regression that features as a covariate the inverse Mills ratio computed on the basis of our firststage estimates.

Due to the non-linearity stemming from the inclusion of the inverse Mills ratio among the regressors, the identification of the parameters of the outcome equation is formally possible even if the vector of covariates in the outcome equation is identical to the vector of covariates in the selection equation. Such functional form-based identification, however, can be plagued by severe multicollinearity and, consequently, large standard errors (see, e.g., Wooldridge 2002: 564; Cameron and Trivedi 2005: 551). In an attempt to obtain more precise parameter estimates, we, therefore, estimate the model using as exclusion restriction the variable Multiple Parties that equals 1 if there is more than one party on either the plaintiff or the defendant side and 0 otherwise (see Table 1). ${ }^{7}$ Intuitively, presence of multiple parties on either plaintiff or defendant side all else equal increases the prospects of an appeal. The number of disputing parties, however, should not affect the likelihood of verdict reversal at the appellate stage, especially after controlling for the full range of other case and party characteristics, as well as judge fixed effects, as featured in column (1) of Table 4.

\subsection{Results}

Table 6 reports the results. In all of the regressions, we control for the full set of party and case characteristics, as well as judge and year-of-filing fixed effects. Column (1) shows the average marginal effect of the duration of judge deliberation on the probability that the case is appealed. The estimated effect is negative, as would be the case if longer judicial deliberation reduced the prospects of an appeal, but statistically insignificant. The average marginal effect of Multiple

\footnotetext{
7 The results based on the Heckman (1979) two-step method without exclusion restrictions are very similar and, thus, omitted.
} 
Parties, our exclusion restriction (not reported), is positive (0.0177), as hypothesized, but statistically insignificant ( $p$-value equals 0.744$)$.

Column (2) of Table 6 shows the relevant coefficient estimate from the OLS regression of the dummy Overturned on the duration of judge deliberation, corrected for sample selection. The results show a statistically significant negative association between the duration of judicial deliberation and the prospects that the judge's verdict is overturned by a higher court. The coefficient on the inverse Mills ratio is statistically insignificant. We thus do not find evidence in favor of sample selection. Column (3) shows the coefficient estimate of interest from the OLS regression of the dummy Overturned on the duration of judge deliberation without sample selection correction. We again find a statistically significant negative association between the duration of judicial deliberation and the prospects that the judge's verdict is overturned by a higher court. The magnitude of the estimate is very similar to that reported in column (2) of Table 6. The estimates in columns (2) and (3) suggest that one-standard-deviation increase in the duration of judicial deliberation (14 days) is all else equal associated with an 11 percent decrease in the prospects that the judge's decision is overturned by a higher court.

In sum, our findings are consistent with the hypothesis that longer (shorter, respectively) duration of judicial deliberation improves (worsens) the quality of judicial decision-making.

\section{Conclusion}

We contribute to the existing empirical literature on courts and judicial behavior by examining a thus far unexplored judicial outcome: the time that a judge takes to deliberate on a case in order to render a verdict. Drawing on a novel dataset of disputes adjudicated at a large Belgian court, we first document the extent of variation in the duration of judicial deliberation. Utilizing survival analysis and exploiting the fact that the administrative allocation of filed cases among 
the serving judges is purposefully independent of party, case, and judge characteristics, we then examine the determinants of the duration of judicial deliberation.

We find that, as anticipated, the duration of judicial deliberation ceteris paribus increases with case complexity. However, selected attributes of the judge and disputing parties, such as the type of judge's prior judicial experience and whether the disputing parties include a legal person, matter as well. Our findings therefore resonate with the legal realists' view that judge characteristics and extralegal factors play an important role in the decision-making in courts (see, e.g., George and Epstein 1992, Danziger et al. 2011). Finally, we show that longer duration of judicial deliberation is associated with better quality of judicial verdicts as measured by the prospects that a case is overturned by a higher court. Thus, for policy-making purposes, any benefit from encouraging faster judicial verdicts, perhaps to combat court delays, must be weighed carefully against the potential losses in the quality of judicial decisions.

Future work could aim to re-assess the validity of our findings by extending our analysis of the causes and consequences of the duration of judicial deliberation in the context of other jurisdictions in Europe and beyond, and by examining other types of disputes. Given the lack of fine-grained micro-level data on judicial decision-making and substantial variation in institutional arrangements of judiciaries across jurisdictions, the empirical study of judicial behavior worldwide constitutes a fruitful avenue for future research. 


\section{References}

Beenstock, Michael and Yoel Haitovsky. 2004. "Does the Appointment of Judges Increase the Output of the Judiciary?" International Review of Law and Economics, 24:3, 351-369.

Belgische Senaat. 2015. Verslag van de Commissie voor de Justitie van 8 maart 2005. Document 3-663/5.

Benjamini, Yoav and Yosef Hochberg. 1995. "Controlling the False Discovery Rate: A Practical and Powerful Approach to Multiple Testing." Journal of the Royal Statistical Society, Series B (Methodological), 57:1, 289-300.

Bielen, Samantha, Wim Marneffe, and Lode Vereeck. 2015. "An Empirical Analysis of Case Disposition Time in Belgium." Review of Law and Economics, 11:2, 293-316.

Bielen, Samantha, Wim Marneffe, and Lode Vereeck. 2014. "A Cross-Country Analysis of the Impact of Regulatory Quality on Commercial Case Disposition Time." European Journal of Law and Economics, 39:3, 455-474.

Botero, Juan Carlos, Rafael La Porta, Florencio López-de-Silanes, Andrei Shleifer and Alexander Volokh. 2003. "Judicial Reform." World Bank Research Observer, 18:1, 61-88.

Boyd, Christina L., Lee Epstein and Andrew D. Martin. 2010. "Untangling the Causal Effects of Sex on Judging." American Journal of Political Science, 54:2, 389-411.

Boyd, Christina L. and David A. Hoffman. 2013. "Litigating toward Settlement." Journal of Law, Economics, and Organization, 29:4, 898-929.

Cameron, A. Colin and Pravin K. Trivedi. 2005. Microeconometrics: Methods and Applications. New York: Cambridge University Press.

Chemin, Matthieu. 2012. "Does Court Speed Shape Economic Activity? Evidence from a Court Reform in India." Journal of Law, Economics, and Organization, 28:3, 460-485.

Choi, Stephen J., Mitu G. Gulati, and Eric A. Posner. 2009. "Are Judges Overpaid: A Skeptical Response to the Judicial Salary Debate." Journal of Legal Analysis, 1:1, 47-117.

Choi, Stephen J., Mitu G. Gulati, and Eric A. Posner. 2010. "Professionals or Politicians: The Uncertain Empirical Case for an Elected rather than Appointed Judiciary." Journal of Law, Economics, and Organization, 26:2, 290-336.

Choi, Stephen J., Mitu G. Gulati, Mirya R. Holman and Eric A. Posner. 2011. "Judging Women." Journal of Empirical Legal Studies, 8:3, 504-532.

Choi, Stephen J., Mitu Gulati, and Eric A. Posner. 2012. "What Do Federal District Judges Want? An Analysis of Publications, Citations, and Reversals." Journal of Law, Economics, and Organization, 28:3, 518-549.

Christensen, Robert K. and John Szmer. 2012. "Examining the Efficiency of the U.S. Courts of Appeals: Pathologies and Prescriptions." International Review of Law and Economics, 32:1, 30-37.

Cleves, Mario, Roberto G. Gutierrez, William Gould, and Yulia V. Marchenko. 2010. An Introduction to Survival Analysis Using Stata, Third Edition. Texas: Stata Press.

Coviello, Decio, Andrea Ichino, and Nicola Persico. 2015. "The Inefficiency of Worker Time Use." Journal of the European Economic Association, 13:5, 906-947.

Cox, David R. 1972. "Regression Models and Life-Tables." Journal of Royal Statistical Society, Series B (Methodological), 34:2, 187-220.

Danziger, Shai, Jonathan Levav, and Liora Avnaim-Pesso. 2011. "Extraneous Factors in Judicial Decisions." Proceedings of the National Academy of Sciences of the United States of America, 108:17, 6889-6892. 
Davis, Sue, Susan Haire and Donald R. Songer. 1993. "Voting Behavior and Gender on the U.S. Courts of Appeals." Judicature, 77:1, 34-64.

Deyneli, Fatih. 2012. "Analysis of Relationship between Efficiency of Justice Services and Salaries of Judges with Two-Stage DEA Method." European Journal of Law and Economics, $34: 3,477-493$.

Di Vita, Giuseppe. 2012. "Factors Determining the Duration of Legal Disputes: An Empirical Analysis with Micro Data." Journal of Institutional and Theoretical Economics, 168:4, 563587.

Dimitrova-Grajzl, Valentina, Peter Grajzl, Atanas Slavov, and Katarina Zajc. 2016. "Courts in a Transition Economy: Case Disposition and the Quantity-Quality Tradeoff in Bulgaria." Economic Systems, 40:1, 18-38.

Dimitrova-Grajzl, Valentina, Peter Grajzl, Janez Sustersic, and Katarina Zajc. 2012a. "Court Output, Judicial Staffing, and the Demand for Court Services: Evidence from Slovenian Courts of First Instance." International Review of Law and Economics, 32:1, 19-29.

Dimitrova-Grajzl, Valentina, Peter Grajzl, Katarina Zajc, and Janez Sustersic. 2012b. "Judicial Incentives and Performance at Lower Courts: Evidence from Slovenian Judge-Level Data." Review of Law and Economics, 8:1, 215-252.

Dimitrova-Grajzl, Valentina, Peter Grajzl, and Katarina Zajc. 2014. "Understanding Modes of Civil Case Disposition: Evidence from Slovenian Courts." Journal of Comparative Economics, 42:4, 924-939.

Djankov, Simeon, Rafael La Porta, Florencio Lopez-de-Silanes, and Andrei Shleifer. 2003. "Courts." The Quarterly Journal of Economics, 118:2, 453-517.

El Bialy, Nora. 2016. "The 2007 Judicial Reform and Court Performance in Egypt." Review of Law and Economics, 12:1, 95-117.

Feld, Lars P. and Stefan Voigt. 2003. "Economic Growth and Judicial Independence: CrossCountry Evidence Using a New Set of Indicators." European Journal of Political Economy, 19:3, 497-527.

Fenn, Paul and Neil Rickman. 2014. "Information and the Disposition of Medical Malpractice Claims: A Competing Risks Analysis." Journal of Law, Economics, and Organization, 30:2, 244-274.

Galanter, Marc. 1974. "Why the 'Haves' Come Out Ahead: Speculations on the Limits of Legal Change." Law and Society Review, 9:1, 95-160.

Galanter, Marc. 2004. "The Vanishing Trial: An Examination of Trials and Related Matters in Federal and State Courts." Journal of Empirical Legal Studies, 1:3, 459-570.

George, Tracey E. and Lee Epstein. 1992. "On the Nature of Supreme Court Decision Making." American Political Science Review, 86:02, 323-337.

Grambsch, Patricia M. and Terry M. Therneau. 1994. "Proportional Hazards Tests and Diagnostics Based on Weighted Residuals." Biometrika, 81:3, 515-526.

Gruhl, John, Cassia Spohn, and Susan Welch. 1981. "Women as Policymakers: The Case of Trial Judges." American Journal of Political Science, 25:2, 308-322.

Heckman, James J. 1979. "Sample Selection Bias as a Specification Error." Econometrica, 47:1, 153-161.

Hoge Raad voor de Justitie. 2014. Memorandum voor de Formateur van de Toekomstige Federale Regering. Brussel. 
Ippoliti, Roberto, Alessandro Melcarne, and Giovanni B. Ramello. 2014. "Judicial Efficiency and Entrepreneurs' Expectations on the Reliability of European Legal Systems." European Journal of Law and Economics, 40:1, 75-94.

Iyer, K.C., N.B. Chaphalkar, and G.A. Joshi. 2008. "Understanding Time Delay Disputes in Construction Contracts." International Journal of Project Management, 26:2, 174-184.

Johnson, Carrie E. 1997. "Rocket Dockets: Reducing Delay in Federal Civil Litigation." California Law Review, 85:1, 225-264.

Mitsopoulos, Michael and Theodore Pelagidis. 2007. "Does Staffing Affect the Time to Dispose Cases in Greek Courts?" International Review of Law and Economics, 27:2, 219-244.

Mitsopoulos, Michael and Theodore Pelagidis. 2010. "Greek Appeals Courts' Quality Analysis and Performance." European Journal of Law and Economics, 30:1, 17-39.

Peresie, Jennifer L. 2005. "Female Judges Matter: Gender and Collegial Decisionmaking in the Federal Appellate Courts." The Yale Law Journal, 114:7, 1759-1790.

Posner, Richard A. 1993. "What Do Judges and Justices Maximize? (The Same Thing Everybody Else Does)." Supreme Court Economic Review, 3:1, 1-41.

Posner, Richard. 1998. "Creating a Legal Framework for Economic Development." The World Bank Research Observer, 13:1, 1-11.

Posner, Richard A. 1996. The Federal Courts: Challenge and Reform. Cambridge, MA: Harvard University Press.

Posner, Richard A. 2000. "Is the Ninth Circuit Too Large? A Statistical Study of Judicial Quality." Journal of Legal Studies, 29:2, 711-719.

Priest, George L. and Benjamin Klein. 1984. "The Selection of Disputes for Litigation." Journal of Legal Studies, 13:1, 1-55.

Ramseyer, Mark J. 2012. "Talent Matters: Judicial Productivity and Speed in Japan." International Review of Law and Economics, 32:1, 38-48.

Rosales-López, Virginia. 2008. "Economics of Court Performance: An Empirical Analysis." European Journal of Law and Economics, 25:3, 231-251.

Schanzenbach, Max M. 2015. "Racial Disparities, Judge Characteristics, and Standards of Review in Sentencing." Journal of Institutional and Theoretical Economics, 171:1, 27-47.

Schneider, Martin R. 2005. "Judicial Career Incentives and Court Performance: An Empirical Study of the German Labour Courts of Appeal." European Journal of Law and Economics, 20:2, 127-144.

Spurr, Stephen J. 1997. "The Duration of Litigation." Law and Policy, 19:3, 285-316.

Stephenson, Matthew C. 2009. "Legal Realism for Economists." The Journal of Economic Perspectives, 23:2, 191-211.

Teitelbaum, Joshua C. 2006. "Age, Tenure and Productivity of the U.S. Supreme Court: Are Term Limits Necessary?" Florida State University Law Review, 34:1, 161-181.

Voigt, Stefan. 2016. "Determinants of Judicial Efficiency: A Survey." European Journal of Law and Economics, forthcoming.

Wooldridge, Jeffrey M. 2002. Econometric Analysis of Cross Section and Panel Data. Cambridge, MA: The MIT Press. 
Table 1: Variable Definitions

\begin{tabular}{|c|c|}
\hline Variable name & Description \\
\hline \multicolumn{2}{|l|}{ Party characteristics } \\
\hline Multiple Parties & Dummy equal to 1 if there is more than one party on either the plaintiff or the defendant side. \\
\hline$\geq 1$ Legal Person & Dummy equal to 1 if at least one party to the case is a legal person. \\
\hline$\geq 1$ Government & Dummy equal to 1 if at least one party to the case is government. \\
\hline$\geq 1$ Party Self-Represented & Dummy equal to 1 if at least one party to the case is not represented by a lawyer. \\
\hline \multicolumn{2}{|l|}{ Case characteristics } \\
\hline Duration of Judge Deliberation & The number of days the judge deliberates on the case prior to articulating a verdict. \\
\hline Claim Value & Value of the claim, in EUR $10,000$. \\
\hline Expert & Dummy equal to 1 if a court expert was assigned to the case. \\
\hline Calendar Parties & Dummy equal to 1 if parties were ever in charge of setting up the pleading calendar. \\
\hline$>2$ Hearings & Dummy equal to 1 if there were more than two hearings scheduled in the case. \\
\hline Pleadings Pages & Total number of pages in the pleadings prepared by the plaintiff and the defendant side. \\
\hline Appealed Default Judgment & Dummy equal to 1 if the case proceeded after an appealed default judgment. \\
\hline Initiated Other Court & Dummy equal to 1 if the case was initiated at a different court. \\
\hline Appealed & Dummy equal to 1 if the case was appealed by the end of our observation window. \\
\hline Overturned & Dummy equal to 1 if a higher court overturned the verdict the end of our observation window. \\
\hline \multicolumn{2}{|r|}{ 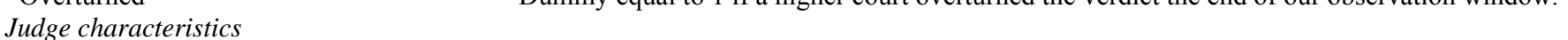 } \\
\hline Female & Dummy equal to 1 if judge is a female. \\
\hline Age & Judge's age in the year of the filing of the case. \\
\hline Years of Experience & Judge's years of experience as a judge in the year of the filing of the case. \\
\hline Judicial Intern Experience & Dummy equal to 1 if the judge has had prior experience as judicial intern. \\
\hline Substitute Judge Experience & Dummy equal to 1 if the judge has had prior experience as substitute judge. \\
\hline Court President Experience & Dummy equal to 1 if the judge has had prior experience as court president. \\
\hline Appellate Judge Experience & Dummy equal to 1 if the judge has had prior experience as appellate judge. \\
\hline
\end{tabular}


Table 2: Descriptive Statistics

\begin{tabular}{|c|c|c|c|c|c|}
\hline Variable & No. Obs. & Mean & Std. Dev. & Min. & Max. \\
\hline \multicolumn{6}{|l|}{ Party Characteristics } \\
\hline Multiple Parties & 631 & 0.3819 & 0.4862 & 0 & 1 \\
\hline$\geq 1$ Legal Person & 631 & 0.8193 & 0.3850 & 0 & 1 \\
\hline$\geq 1$ Government & 631 & 0.0111 & 0.1048 & 0 & 1 \\
\hline$\geq 1$ Party Self-Represented & 631 & 0.2520 & 0.4345 & 0 & 1 \\
\hline \multicolumn{6}{|l|}{ Case characteristics } \\
\hline Duration of Judge Deliberation (in days) & 597 & 30.18 & 14.11 & 3 & 99 \\
\hline Claim Value (in EUR) & 631 & $29,782.1$ & $108,846.3$ & 282.0 & $2,040,397.0$ \\
\hline Expert & 631 & 0.1347 & 0.3417 & 0 & 1 \\
\hline Calendar Parties & 631 & 0.5594 & 0.4968 & 0 & 1 \\
\hline$>2$ Hearings & 631 & 0.0951 & 0.2936 & 0 & 1 \\
\hline Pleadings Pages & 631 & 17.1 & 15.4 & 0 & 111 \\
\hline Appealed Default Judgment & 631 & 0.0190 & 0.1367 & 0 & 1 \\
\hline Initiated Other Court & 631 & 0.0507 & 0.2196 & 0 & 1 \\
\hline Appealed & 304 & 0.3026 & 0.4602 & 0 & 1 \\
\hline Overturned & 92 & 0.3587 & 0.4822 & 0 & 1 \\
\hline \multicolumn{6}{|l|}{ Judge characteristics } \\
\hline Female & $631[19]$ & $0.6149[.3684]$ & $0.4870[.4956]$ & $0[0]$ & $1[1]$ \\
\hline Age & $631[19]$ & $38.89[43.64]$ & $7.49[7.71]$ & $30[32]$ & $62[62]$ \\
\hline Years of Experience & $631[19]$ & $4.46[7.90]$ & $4.17[6.46]$ & $0[1]$ & $27[27]$ \\
\hline Judicial Intern Experience & $631[19]$ & $0.6830[0.4211]$ & $0.4657[0.5073]$ & $0[0]$ & $1[1]$ \\
\hline Substitute Judge Experience & $631[19]$ & $0.1664[0.2632]$ & $0.3727[0.4524]$ & $0[0]$ & $1[1]$ \\
\hline Court President Experience & $631[19]$ & $0.0032[0.0526]$ & $0.0563[0.2294]$ & $0[0]$ & $1[1]$ \\
\hline Appellate Judge Experience & $631[19]$ & $0.1315[0.1579]$ & $0.3383[0.3746]$ & $0[0]$ & $1[1]$ \\
\hline
\end{tabular}

Notes: The variables Appealed and Overturned are defined only for cases resolved prior to March 1, 2012 (see text for discussion). The numbers in the brackets report descriptive statistics for judge characteristics at the judge level (as opposed to case level). 
Table 3: Summary of Hypotheses

\begin{tabular}{lc}
\hline \hline Explanatory variable & Hypothesized Effect on \\
Duration of Judicial Deliberation
\end{tabular}


Table 4: Hazard Ratios, Cox Model

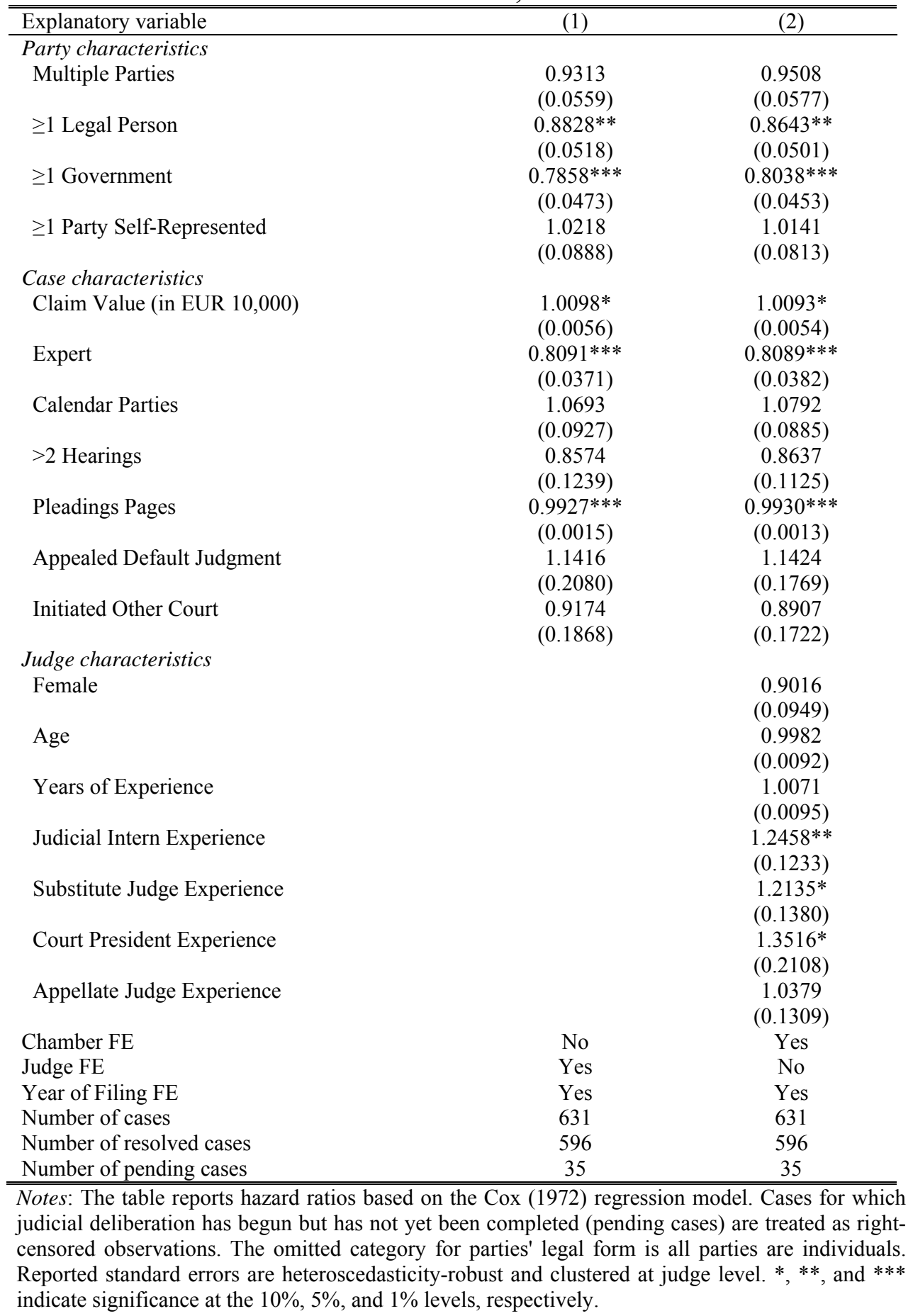


Table 5: Hazard Ratios, Alternative Model Specifications

\begin{tabular}{|c|c|c|c|c|c|c|}
\hline \multirow{2}{*}{ Explanatory variable } & \multicolumn{2}{|c|}{ Stratified Cox Model } & \multicolumn{4}{|c|}{ Weibull Model } \\
\hline & (1) & $(2)$ & (3) & $(4)$ & $(5)$ & $(6)$ \\
\hline \multicolumn{7}{|l|}{ Party characteristics } \\
\hline \multirow[t]{2}{*}{ Multiple Parties } & 0.9826 & 0.9810 & 0.9403 & 0.9927 & 0.9581 & 0.9834 \\
\hline & $(0.0588)$ & $(0.0583)$ & $(0.1507)$ & $(0.1428)$ & $(0.1562)$ & $(0.1507)$ \\
\hline \multirow[t]{2}{*}{$\geq 1$ Legal Person } & $0.8558 * * *$ & $0.8332 * * *$ & $0.7307 * * *$ & $0.7297 * * *$ & $0.7226^{* * *}$ & $0.7201 * * *$ \\
\hline & $(0.0462)$ & $(0.0566)$ & $(0.0421)$ & $(0.0571)$ & $(0.0508)$ & $(0.0619)$ \\
\hline \multirow[t]{2}{*}{$\geq 1$ Government } & $0.7907 * * *$ & $0.7774 * *$ & 1.2402 & 1.0969 & 1.0700 & 0.9791 \\
\hline & $(0.0697)$ & $(0.0782)$ & $(0.1852)$ & $(0.0995)$ & $(0.1760)$ & $(0.0975)$ \\
\hline \multirow[t]{2}{*}{$\geq 1$ Party Self-Represented } & 0.9907 & 1.0058 & 1.0662 & 1.0854 & 1.0445 & 1.0592 \\
\hline & $(0.0710)$ & $(0.0690)$ & $(0.0857)$ & $(0.1050)$ & $(0.1312)$ & $(0.1510)$ \\
\hline \multicolumn{7}{|l|}{ Case characteristics } \\
\hline \multirow[t]{2}{*}{ Claim Value (in EUR 10,000) } & 1.0068 & 1.0091 & $1.0105 * * *$ & $1.0089 * *$ & $1.0130 * * *$ & $1.0121 * * *$ \\
\hline & $(0.0056)$ & $(0.0066)$ & $(0.0039)$ & $(0.0044)$ & $(0.0041)$ & $(0.0041)$ \\
\hline \multirow[t]{2}{*}{ Expert } & $0.8446 * * *$ & $0.8304 * * *$ & $0.6435 * * *$ & $0.7008 * * *$ & $0.6266^{* * *}$ & $0.6725 * * *$ \\
\hline & $(0.0374)$ & $(0.0424)$ & $(0.0612)$ & $(0.0796)$ & $(0.0623)$ & $(0.0707)$ \\
\hline \multirow[t]{2}{*}{ Calendar Parties } & 1.0696 & 1.0764 & 1.1608 & 1.1885 & 1.1543 & 1.1829 \\
\hline & $(0.0900)$ & $(0.0912)$ & $(0.2265)$ & $(0.2635)$ & $(0.2458)$ & $(0.2764)$ \\
\hline \multirow[t]{2}{*}{$>2$ Hearings } & 0.8142 & 0.8364 & 1.0313 & 1.0346 & 1.0868 & 1.0826 \\
\hline & $(0.1415)$ & $(0.1370)$ & $(0.2572)$ & $(0.2500)$ & $(0.3107)$ & $(0.2995)$ \\
\hline \multirow[t]{2}{*}{ Pleadings Pages } & $0.9929 * * *$ & $0.9932 * * *$ & $0.9872 * * *$ & $0.9894 * * *$ & $0.9848 * * *$ & $0.9864 * * *$ \\
\hline & $(0.0015)$ & $(0.0013)$ & $(0.0023)$ & $(0.0023)$ & $(0.0029)$ & $(0.0025)$ \\
\hline \multirow[t]{2}{*}{ Appealed Default Judgment } & 1.1351 & 1.1360 & $1.4420 * * *$ & $1.5207 * * *$ & $1.3904 * *$ & $1.4399 * * *$ \\
\hline & $(0.1849)$ & $(0.1818)$ & $(0.1750)$ & $(0.1669)$ & $(0.1916)$ & $(0.1958)$ \\
\hline \multirow[t]{2}{*}{ Initiated Other Court } & 0.9230 & 0.9335 & 0.8645 & 0.8724 & 0.8097 & 0.8117 \\
\hline & $(0.1905)$ & $(0.1708)$ & $(0.3130)$ & $(0.2985)$ & $(0.3413)$ & $(0.3270)$ \\
\hline \multicolumn{7}{|l|}{ Judge characteristics } \\
\hline \multirow[t]{2}{*}{ Female } & & 0.8880 & & 1.0083 & & 0.9702 \\
\hline & & $(0.1122)$ & & $(0.2006)$ & & $(0.2214)$ \\
\hline \multirow[t]{2}{*}{ Age } & & 0.9987 & & 1.0236 & & 1.0163 \\
\hline & & $(0.0108)$ & & $(0.0188)$ & & $(0.0208)$ \\
\hline \multirow[t]{2}{*}{ Years of Experience } & & 1.0070 & & 0.9796 & & 0.9851 \\
\hline & & $(0.0107)$ & & $(0.0238)$ & & $(0.0239)$ \\
\hline \multirow[t]{2}{*}{ Judicial Intern Experience } & & $1.3062 * *$ & & $1.3415^{*}$ & & $1.3417^{*}$ \\
\hline & & $(0.1518)$ & & $(0.2194)$ & & $(0.2253)$ \\
\hline \multirow[t]{2}{*}{ Substitute Judge Experience } & & $1.2744^{*}$ & & $1.7685 * * *$ & & $1.7841 * * *$ \\
\hline & & $(0.1793)$ & & $(0.3477)$ & & $(0.3928)$ \\
\hline Court President Experience & & $1.3474^{*}$ & & 1.3174 & & 1.3912 \\
\hline & & $(0.2335)$ & & $(0.4130)$ & & $(0.4720)$ \\
\hline Appellate Judge Experience & & 1.0176 & & 0.9307 & & 0.9470 \\
\hline & & $(0.1490)$ & & $(0.1736)$ & & $(0.2252)$ \\
\hline Chamber FE & No & No & No & Yes & No & Yes \\
\hline Judge FE & No & No & Yes & No & Yes & No \\
\hline Year of Filing FE & Yes & Yes & Yes & Yes & Yes & Yes \\
\hline Unshared frailty & No & No & No & No & Yes & Yes \\
\hline Number of cases & 631 & 631 & 631 & 631 & 631 & 631 \\
\hline Number of resolved cases & 596 & 596 & 596 & 596 & 596 & 596 \\
\hline Number of pending cases & 35 & 35 & 35 & 35 & 35 & 35 \\
\hline
\end{tabular}

Number of pending cases

Notes: The table reports hazard ratios based on the Stratified Cox regression model (columns (1) and (2)) and Weibull model (columns (3) through (6)). In distribution. Cases for which judicial deliberation has begun but has not yet been completed (pending cases) are treated as right-censored observations. The omitted category for parties' legal form is all parties are individuals. Reported standard errors are heteroscedasticity-robust and clustered at judge level. *,**, and $* * *$ indicate significance at the $10 \%, 5 \%$, and $1 \%$ levels, respectively. 
Table 6: The Duration of Judge Deliberation and Adjudicatory Quality

\begin{tabular}{|c|c|c|c|}
\hline & \multicolumn{2}{|c|}{ Heckman Two-Step } & \multirow{2}{*}{$\begin{array}{c}\text { OLS } \\
\text { (3) Overturned }\end{array}$} \\
\hline Explanatory variable & (1) Appealed & (2) Overturned & \\
\hline Duration of Judge Deliberation & $\begin{array}{l}-0.0012 \\
(0.0022)\end{array}$ & $\begin{array}{c}-0.0082^{*} \\
(0.0045)\end{array}$ & $\begin{array}{c}-0.0076^{* *} \\
(0.0025)\end{array}$ \\
\hline Party Characteristics & Yes & Yes & Yes \\
\hline Case Characteristics & Yes & Yes & Yes \\
\hline Judge FE & Yes & Yes & Yes \\
\hline Year of Filing FE & Yes & Yes & Yes \\
\hline Inverse Mills ratio & & $\begin{array}{c}0.5518 \\
(0.6003)\end{array}$ & \\
\hline Number of observations & \multicolumn{2}{|c|}{304} & 92 \\
\hline Censored observations & \multicolumn{2}{|c|}{212} & \\
\hline Uncensored observations & \multirow{2}{*}{\multicolumn{2}{|c|}{92}} & \\
\hline R-squared & & & 0.3087 \\
\hline
\end{tabular}

Notes: The first two columns in the table report results based on the Heckman (1979) two-step estimation method for the subsample of cases for which verdict was issued by March 1, 2012 (see text for discussion). For the probit estimates of the effect of duration of judge deliberation in the selection equation (Appealed), the table reports the average marginal effect. The outcome equation (Overturned) is modeled as a linear probability model. As the exclusion restriction we use the variable Multiple Parties (see Table 1). The third column reports OLS results based on the linear probability model for Overturned; reported standard errors are heteroscedasticity-robust and clustered at judge level. *, **, and $* * *$ indicate significance at the $10 \%, 5 \%$, and $1 \%$ levels, respectively. 
Figure 1: Kernel density estimate for duration of judge deliberation

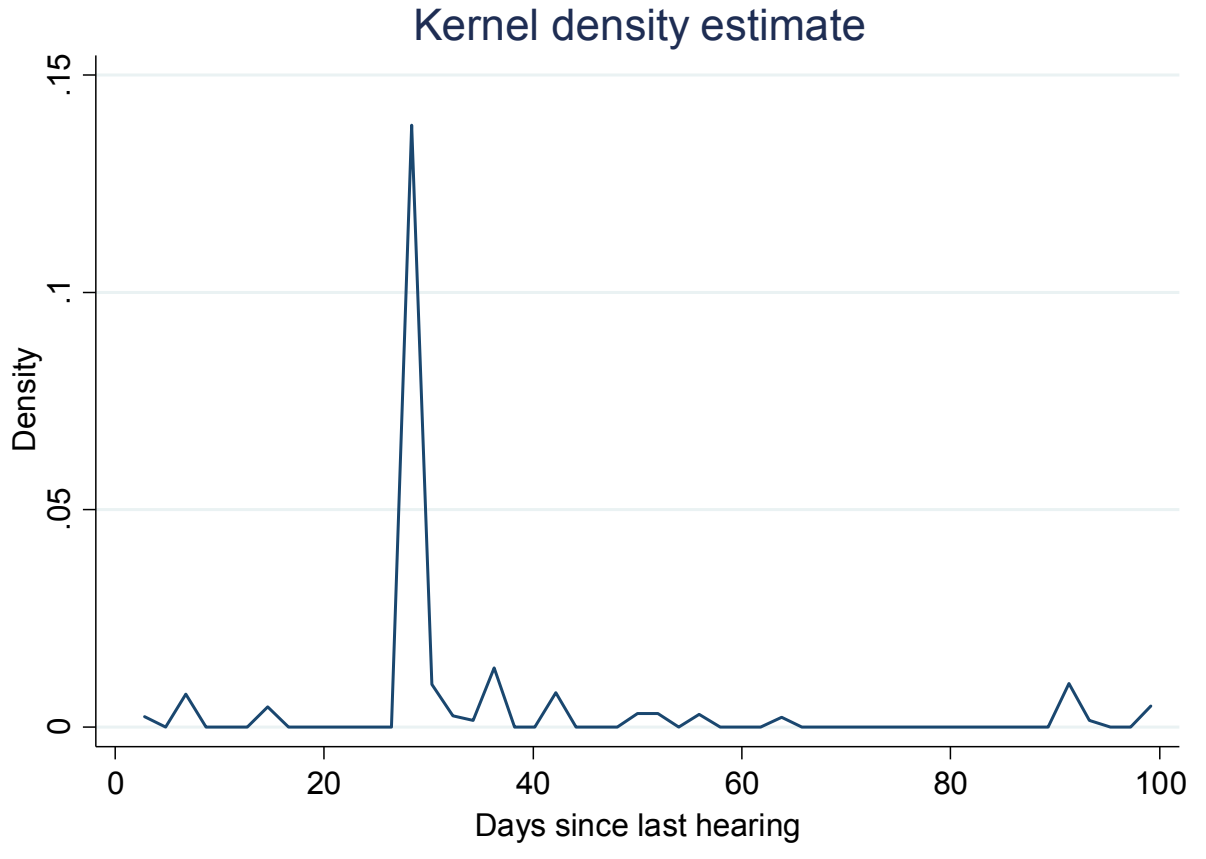


Figure 2: Kaplan-Meier survival estimate for announcement of verdict

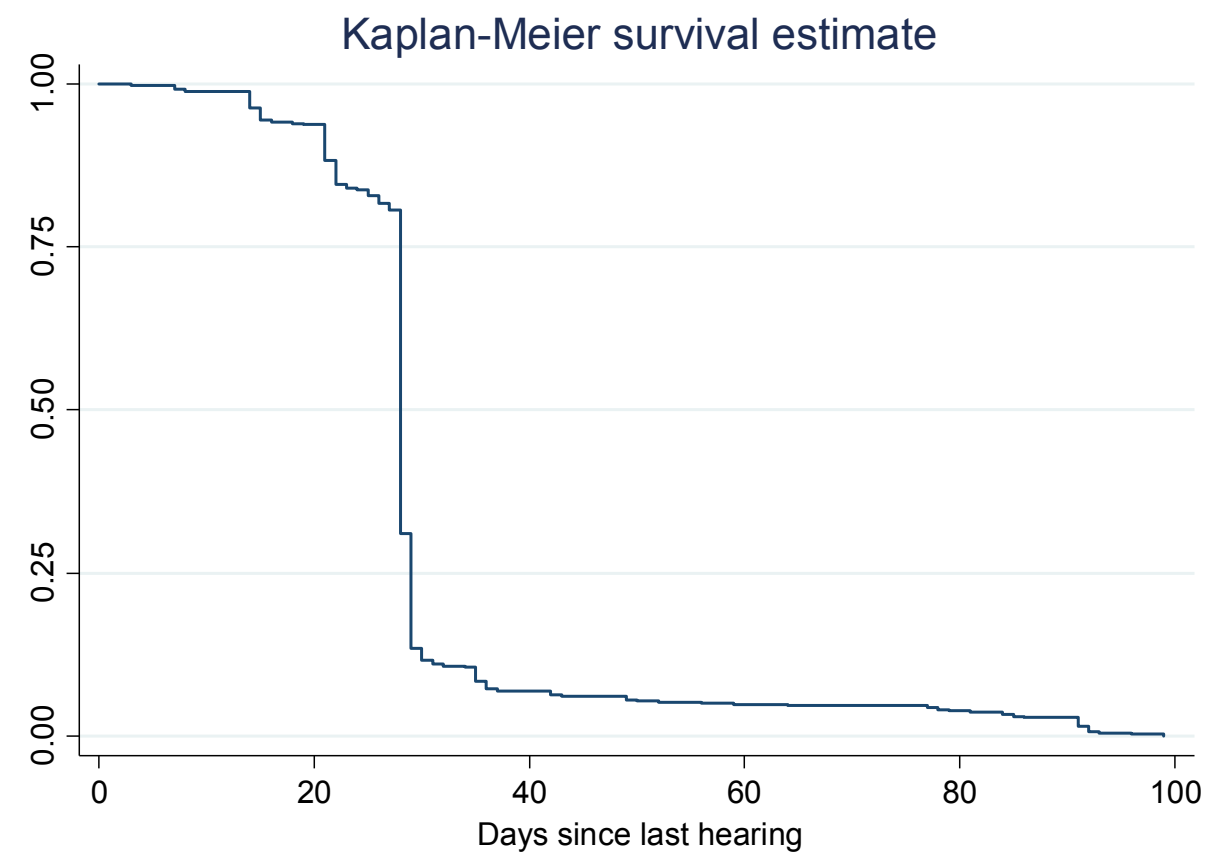


Figure 3: Smoothed hazard estimate for announcement of verdict

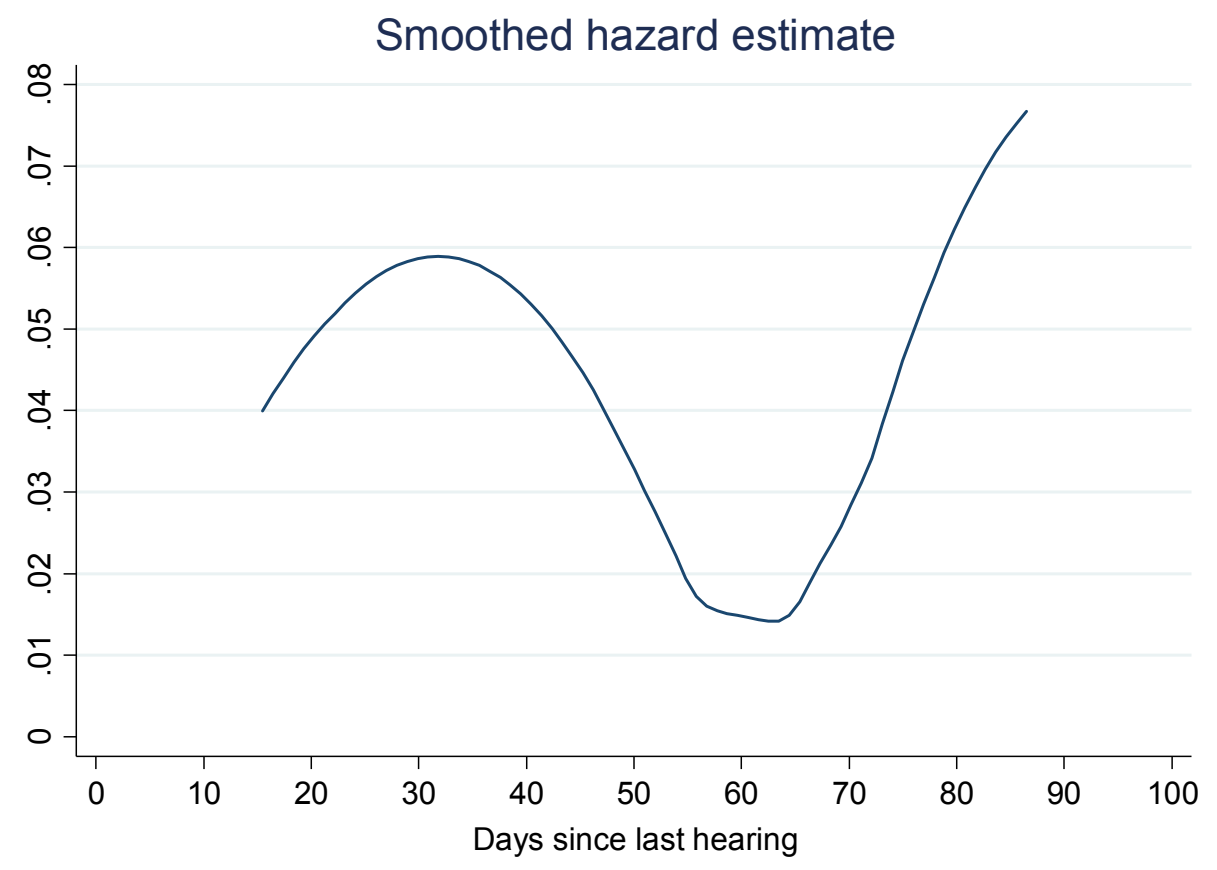




\section{Appendix}

Table A1: Duration of Judge Deliberation, Distribution by Days

\begin{tabular}{|c|c|c|c|}
\hline Duration (in days) & Frequency & Percent & Cumulative percent \\
\hline 3 & 1 & 0.17 & 0.17 \\
\hline 7 & 4 & 0.67 & 0.84 \\
\hline 8 & 2 & 0.34 & 1.17 \\
\hline 14 & 15 & 2.52 & 3.69 \\
\hline 15 & 11 & 1.85 & 5.54 \\
\hline 16 & 2 & 0.34 & 5.87 \\
\hline 18 & 1 & 0.17 & 6.04 \\
\hline 19 & 1 & 0.17 & 6.21 \\
\hline 21 & 33 & 5.54 & 11.74 \\
\hline 22 & 22 & 3.69 & 15.44 \\
\hline 23 & 3 & 0.50 & 15.94 \\
\hline 24 & 2 & 0.34 & 16.28 \\
\hline 25 & 5 & 0.84 & 17.11 \\
\hline 26 & 7 & 1.17 & 18.29 \\
\hline 27 & 6 & 1.01 & 19.30 \\
\hline 28 & 296 & 49.66 & 68.96 \\
\hline 29 & 105 & 17.62 & 86.58 \\
\hline 30 & 11 & 1.85 & 88.42 \\
\hline 31 & 3 & 0.50 & 88.93 \\
\hline 32 & 2 & 0.34 & 89.26 \\
\hline 34 & 1 & 0.17 & 89.43 \\
\hline 35 & 13 & 2.18 & 91.61 \\
\hline 36 & 7 & 1.17 & 92.79 \\
\hline 37 & 2 & 0.34 & 93.12 \\
\hline 42 & 3 & 0.50 & 93.62 \\
\hline 43 & 2 & 0.34 & 93.96 \\
\hline 49 & 3 & 0.50 & 94.46 \\
\hline 50 & 1 & 0.17 & 94.63 \\
\hline 52 & 1 & 0.17 & 94.80 \\
\hline 56 & 1 & 0.17 & 94.97 \\
\hline 59 & 1 & 0.17 & 95.13 \\
\hline 64 & 1 & 0.17 & 95.30 \\
\hline 77 & 2 & 0.34 & 95.64 \\
\hline 78 & 2 & 0.34 & 95.97 \\
\hline 79 & 1 & 0.17 & 96.14 \\
\hline 81 & 1 & 0.17 & 96.31 \\
\hline 84 & 2 & 0.34 & 96.64 \\
\hline 85 & 2 & 0.34 & 96.98 \\
\hline 86 & 1 & 0.17 & 97.15 \\
\hline 91 & 8 & 1.34 & 98.49 \\
\hline 92 & 5 & 0.84 & 99.33 \\
\hline 93 & 1 & 0.17 & 99.50 \\
\hline 96 & 1 & 0.17 & 99.66 \\
\hline 99 & 2 & 0.34 & 100.00 \\
\hline
\end{tabular}

Notes: The table presents the distribution of duration times (in days) for 596 cases, all resolved via trial-based verdict, which are part of the estimating sample for the results reported in Tables 4 and 5 . 
Table A2: Summary of Tests of Random Assignment of Cases to Judges

\begin{tabular}{|c|c|c|c|c|c|}
\hline Explanatory variable & $\begin{array}{c}\text { Number of } \\
\text { Tests }\end{array}$ & $\begin{array}{c}\text { Rejections } \\
\text { (count) } \\
\text { at } 5 \% \\
\text { significance } \\
\text { level }\end{array}$ & $\begin{array}{c}\text { Rejections } \\
\text { (fraction) } \\
\text { at } 5 \% \\
\text { significance } \\
\text { level }\end{array}$ & $\begin{array}{c}\text { Rejections } \\
\text { (count) } \\
\text { at corrected } \\
\text { significance } \\
\text { level }\end{array}$ & $\begin{array}{c}\text { Rejections } \\
\text { (fraction) } \\
\text { at corrected } \\
\text { significance } \\
\text { level }\end{array}$ \\
\hline Multiple Parties & 6 & 0 & 0 & 0 & 0 \\
\hline$\geq 1$ Legal Person & 5 & 0 & 0 & 0 & 0 \\
\hline$\geq 1$ Government & 5 & 1 & 0.200 & 0 & 0 \\
\hline$\geq 1$ Party Self-Represented & 5 & 0 & 0 & 0 & 0 \\
\hline Claim Value $>30,000$ & 6 & 1 & 0.167 & 0 & 0 \\
\hline Expert & 5 & 0 & 0 & 0 & 0 \\
\hline Calendar Parties & 6 & 1 & 0.167 & 0 & 0 \\
\hline$>2$ Hearings & 5 & 0 & 0 & 0 & 0 \\
\hline Pleadings Pages $>17.1$ & 6 & 1 & 0.167 & 0 & 0 \\
\hline Appealed Default Judgment & 5 & 0 & 0 & 0 & 0 \\
\hline Initiated Other Court & 5 & 0 & 0 & 0 & 0 \\
\hline Overall & 59 & 4 & 0.068 & 0 & 0 \\
\hline
\end{tabular}

Notes: The table summarizes the evidence on the random assignment of cases to judges within chambers. We conducted Fisher's tests of independence between judge identity and eleven different discrete case characteristics (i.e. one test per case characteristic per chamber). Claim Value $>30,000$ is a dummy equal to 1 if Claim Value (see Table 1) exceeds EUR 30,000 and 0 otherwise. Pleadings Pages $>17.1$ is a dummy equal to 1 if Pleadings Pages (see Table 1) exceeds the sample average (see Table 2) and 0 otherwise. Tests in the first column is the number of tests. The total number of tests is smaller than 77 (11 case characteristics per seven chambers) because one the cases adjudicated in one of the chambers are adjudicated by only one judge and because the independence test could not be conducted in a few cases due to lack of sufficient degrees of freedom. Rejections in the second and third column are the number of tests for which the $p$-value is smaller than 0.05 . Rejections at corrected significance level in the fourth and fifth column are the number of tests for which the $p$-value is smaller than the value suggested by Benjamini and Hochberg (1995) as means of controlling for familywise error rate problem in multiple hypothesis testing. The results reported in the fourth and fifth column are identical if we instead use the standard Bonferroni approach to multiple hypothesis testing (see Benjamini and Hochberg 1995: 295). 